\title{
A touch of cerebral palsy
}

A mother came into my clinic with her ex-premature baby who had been through the mill of neonatal intensive care but appeared to be doing very well. After we had finished the consultation and I had praised her and her baby for the excellent progress they both were making, she asked me what I thought of another doctor's opinion, that her daughter had "a touch of cerebral palsy". The physiotherapist and I agreed that her daughter did not have cerebral palsy, and I reassured her, but asked whether she hadn't been distressed at the diagnosis. "No" she replied "because you had always warned me of the risk". Oh that breaking the news of cerebral palsy and explaining it to parents was so simple!

In a paper in last month's Archives of Disease in Childhood, Baird and colleagues discuss the thorny problem of how to disclose the diagnosis of cerebral palsy and how we might improve practice. ${ }^{1}$ In their study, dissatisfaction with the structure and manner of disclosure of diagnosis was reported by $20 \%$ and $23 \%$ of 107 mothers, respectively and $43 \%$ expressed dissatisfaction with the information given at that time. In particular, lower satisfaction was found among the mothers of more premature children, mothers with more severely disabled children and worse depression scores, and not surprisingly, those taking legal action.

Does this study have implications for neonatologists and what are they?

\section{Improving current practice}

Baird and colleagues develop guidelines for disclosure of diagnosis which are sensible and to a large extent derived form the work of Cunningham and colleagues over the disclosure of a diagnosis of Down's syndrome ${ }^{2}$ : tell both parents together with their child and a third party if possible, in a private place without interruptions; offer parents a chance to be alone; be clear, direct, and honest; and give accurate information with structured rapid follow up. These principles are difficult to fault and are often practised well in the neonatal intensive care setting where breaking difficult news to parents is part of routine practice, contrary to the assumption of Baird et al. The use of tape recordings of discussions may be of value to the family and to the staff looking after them, and a way of ensuring that everyone knows what is said to a couple. These practices are well described and can be audited. ${ }^{3}$

In a busy outpatient clinic, where you are unexpectedly and genuinely concerned about a child who has clear cerebral palsy and wish to make a referral for support, setting the scene can be very difficult. Parents expect honest answers and not to be "fobbed off". It is rarely ideal but rapid follow up and an appointment outside the clinic setting can usually be arranged, giving some time to arrange the other critical follow up strategies. Waiting until the next clinic slot is not usually a satisfactory option. Prognostication is fraught with problems and it is difficult to get the pitch of information about right. A blend of optimism and reality tends to err on the side of good news, hence the excess of parents who felt poorly informed. The way in which disclosure is managed may alter the whole approach of the parent to their child's condition. ${ }^{4}$ The development of such skills must be seen as part of continuing professional development for neonatologists

Multidisciplinary neonatal follow up is also a major aid to getting children into the disability services, with either a physiotherapist or developmental paediatrician (and others) working alongside the neonatal team in the clinic setting and introducing the parents to the concepts of disability. Early referral of high risk infants for prospective physiotherapy may make relatively modest benefits for later outcome $\mathrm{e}^{5}$ but parents value this support and are more accepting of the diagnosis of cerebral palsy when it is confirmed. The role of the physiotherapist as a skilled helper ${ }^{6}$ in this situation may be invaluable, but demands acknowledgement and has implications for their training.

\section{Neonatal training schemes}

Until recently, UK neonatal training was by apprenticeship and unstructured. In 1995 the British Association of Perinatal Medicine published a set of neonatal syllabuses in which the breadth of training for neonatal subspecialists and for those wishing to develop a special interest in neonatal medicine was described. ${ }^{7}$ These contained clear guidance that communication skills, developmental assessment, and a period attached to a follow up programme or child development centre are important parts of training for a neonatologist. Too often this experience is not gained in a structured manner. Too often it is the trainee who identifies the disability and breaks the news (or gives the game away!). Baird and colleagues rightly suggest that learning how to approach disclosure is not best done on the job but by using formal training sessions. This has support in the plethora of training scenarios that are developing in critical care. As the Royal College of Paediatrics and Child Health develops its new competency based syllabus the knowledge, skills, and experience of breaking such news to parents will continue to be an integral part; training scheme coordinators must develop training strategies in these areas.

\section{Forewarned is forearmed}

Why was the mother described in the first paragraph so accepting of the trite description of cerebral palsy? I suspect it was because we had opened discussion about disability, because of prematurity and the complications we had observed during the neonatal admission, and that she understood that the surveillance we were providing was directed to detection of disability, and not confirmation of normality as is often the case.

Parents are generally poorly informed about risks and outcomes for their premature child, despite the immense support given throughout neonatal intensive care. There is a great reliance on the presence or absence of structural brain lesions in how parents are counselled-that reliance may be misplaced. ${ }^{8}$ Increasingly we are seeing cerebral palsy in children with "normal" ultrasound scans, often in the most immature. There is also increasing evidence that severe developmental delay is a common and important disability, ${ }^{9}$ and complex patterns of cerebral palsy are very 
common in the most immature. Prediction is complicated by the fact that a proportion of infants will develop transient patterns of neurological abnormality that may require intervention but resolve over the second year. ${ }^{10}$

Parents use hope and denial as defence mechanisms in the unexpected crisis following premature birth; leading them through to realistic expectations is an important function of the counselling that occurs in neonatal intensive care. National data are now available for disability rates at 30 months of age in extremely preterm infants. ${ }^{9}$ Many regions also collect data on disability that can be used to inform parents. Hospitals providing neonatal intensive care should collect information on outcomes to inform their practice. ${ }^{11}$ Using data such as these, the neonatologist has a duty to inform and explain outcomes to parents as part of the counselling process that accompanies intensive care. Parents deserve to be aware of the potential outcomes for their child using contemporary and unbiased information. Many will explore internet sites relating to prematurity and they need to be able to put the information they access into a proper context and also feel free to discuss it with their child's carers.

Yes, we should all now get disclosure right, difficult though it may be on occasions. We should, however, start to think about preparing parents by explaining risk. The later detection of cerebral palsy and disclosure of diagnosis will come as less of a surprise, and concerns and worries may be openly discussed in the follow up clinic. We need to train ourselves in this area and equip trainees for the task. In the year 2000 a "touch of cerebral palsy" should be a thing of the past.

NEIL MARLOW

Professor of Neonatal Medicine, Academic Division of Child Health,

School of Human Development, Level E East Block,

Queens Medical Centre, University of Nottingham,

Nottingham NG7 2UH, UK

neil.marlow@nottingham.ac.uk

1 Baird GB, McConachie H, Scrutton D. Improving practice: disclosure of the diagnosis of cerebral palsy. Arch Dis Child 2001;83:475-80.

2 Cunningham CC, Morgan PA, McGucken RB. Down's syndrome: is dissatsfaction with disclosure of diagnosis inevitable? Dev Med Child Neurol 1984;26:33-9.

3 North Western Regional Advisory Group for Learning Disability Services. Breaking the news: a resource for developing guidelines of good practice, procedures and training in informing parents of a diagnosis of a child's impairment. Blackburn: Calderstones, North Western Regional Health Authority, 1992.

4 Weindling AM, Hallam P, Gregg J, Klenka H, Rosenbloom L, Hutton JL. A randomized controlled trial of early physiotherapy for high-risk infants. Acta Paediatr 1996;85:1107-11.

5 Davis H. Counselling parents of children with chronic illness or disability. Leicester: BPS Books, 1993:78-82.

6 Egan G. The skilled helper, 3rd edn. Monterey: Brooks/Cole, 1986.

7 British Association of Perinatal Medicine. Higher specialist training syllabusneonatal medicine. London: BAPM, 1996.

8 Wood N, Marlow N. Neurological and developmental morbidity in children $<26$ weeks gestation at 2.5 years age [abstract 1526]. Pediatr Res 1999:41.

9 Wood NS, Marlow N, Costeloe K, Gibson AT, Wilkinson AR, for the EPICure Study Group. Neurologic and developmental disability after extremely preterm birth. $N$ Engl F Med 2000;343:378-84.

10 Drillien CM. The prognostic significance of abnormal neurological signs. Dev Med Child Neurol 1972;14:575-84.

11 British Association of Perinatal Medicine. Standards for hospitals providing neonatal intensive care. London: BAPM, 1995.

\section{Rapid responses}

Letters on the following papers have been published recently as rapid responses on the ADC website. To read these letters visit www.archdischild.com and click on "read rapid responses":

Feeding issues in preterm infants. R J Cooke, N D Embleton. Arch Dis Child Fetal Neonatal Ed 2000;83:215-8.

Sex differences in outcomes of very low birthweight infants: the newborn male disadvantage. D K Stevenson, J Verter, A A Fanaroff, et al. Arch Dis Child Fetal Neonatal Ed 2000;83:182-5.

Early postnatal dexamethasone treatment and increased incidence of cerebral palsy. E S Shinwell, M Karplus, D Reich, et al. Arch Dis Child Fetal Neonatal Ed 2000;83:177-81.

Long term outcome of twin-twin transfusion syndrome. R B Cincotta, P H Gray, G Phythian, et al. Arch Dis Child Fetal Neonatal Ed 2000;83:171-6.

Antenatal steroids and the developing brain. A Whitelaw, M Thoresen. Arch Dis Child Fetal Neonatal Ed 2000;83:154-7.

Promising stratagems for reducing the burden of neonatal sepsis. N Modi, R Carr. Arch Dis Child Fetal Neonatal Ed 2000;83:150-3.

The impact of diagnostic delay on the course of acute appendicitis. V C Cappendijk, F W J Hazebroek. Arch Dis Child 2000;83:64-6.

Premedication before intubation in UK neonatal units. S Whyte, G Birrell, J Wyllie. Arch Dis Child Fetal Neonatal Ed 2000;82:38-41.

Early motor and mental development in very preterm infants with chronic lung disease. M Katz-Salamon, E M Gerner, B Jonsson, et al. Arch Dis Child Fetal Neonatal Ed 2000;83:1-6.

Weaning strategy with inhaled nitric oxide treatment in persistent pulmonary hypertension of the newborn. H Aly, R Sahni, J-T Wung. Arch Dis Child Fetal Neonatal Ed 1998;76:118-22.

If you would like to post an electronic response to these or any other articles published in the journal, please go to the website, access the article in which you are interested, and click on "eLetters: Submit a response to this article" in the box in the top right hand corner. 